\title{
Study on Osteopontin and Its Clinical Application to Ovarian Cancer
}

\section{Lihong Bao}

Medical College, Inner Mongolia University for the Nationalities, Tongliao, Inner Mongolia, 028000, China

baolihong71@163.com

Keywords: Osteopontin (OPN), Ovarian Cancer, Clinical Application

Abstract. Osteopontin (OPN) is a kind of phosphorylated acidic glycoprotein, human beings' osteoclasts, macrophages, T cells, and vascular smooth muscle cells can secrete OPN, the gene is located on chromosome $4 \mathrm{q} 13$. OPN has a function of adhesion to protein, which can be combined with $\mathrm{CD}_{44}$, integrin $\alpha_{\mathrm{v}} \beta_{3}$ and $\alpha_{\mathrm{v}} \beta_{5}$, OPN is also involved in bone remodeling, the formation of new blood vessel and the reflection of inflammation. OPN can play the synergistic function in tumor metastasis. In this paper, it takes the introduction of biological function of OPN. As for the aspect of early diagnosis of ovarian cancer and prognosis monitoring, it can be used as the supplement of $\mathrm{CA}_{125}$ and markers of other cytokines.

\section{Introduction}

The mortality rate of ovarian cancer can rank the first place among gynecologic tumors, and the incidence rate has been rising in recent years, the overall five-year survival rate is about $30 \%$. Different patients in different period can have great difference in prognosis. The cause of being dead for patients with ovarian cancer is not limited to the primary tumor itself, which is often caused by the reason of the distant metastasis and recurrence. About three fourths of patients had been in stage III-IV, which mainly dues to the lack of effective method for the detection of tumor metastasis. Therefore, through the effective diagnostic index to detect those patients at high risk of distant metastasis and recurrence, so as to have effective treatment on these patients, which can significantly improve the survival rate and survival time, improve the quality of life for patients with ovarian cancer and reduce the mortality, at the same time. In recent years, many studies have showed that expression of osteopontin and its ligands can be expressed in a variety of tumors, osteopontin (OPN) can transduct the pathway to promote cell survival through the activation of $\mathrm{CD}_{44} \mathrm{~V}_{6}$ mediated signal, which also can improve the ability of chemotaxis, homing, adhesion, as well as the invasiveness ability of tumors.

\section{The Biological Function of OPN}

OPN is a kind of phosphorylated acidic glycoprotein, containing Arg-Gly-ASP (shorted for RGD structure) residues, its relative molecular mass is about 325000. human beings' osteoclasts, macrophages, T cells, and vascular smooth muscle cells can secrete OPN. While the gene of OPN is located on chromosome 4q13, which consists of seven exons and six introns. At the same time, its molecular structure is composed of signal peptide sequence, seven to ten consecutive sequences of ASP, RGD domains, $\alpha_{9} \beta_{1} / \alpha_{4} \beta_{1}$ domains and heparin combined domains. Molecular central region can be divided into two functional areas by a variety of thrombin protease, after the terminal of $\mathrm{N}$ through phosphorylation, it can be combined with the integrin receptor binding, especially having strong specificity to the energies of integrin $\alpha_{\mathrm{v}} \beta_{3}$ and $\alpha_{\mathrm{v}} \beta_{5}$; the terminal of $C$ and adhesion molecule $\mathrm{CD}_{44}$ can be combined with the splice variant $\mathrm{V}_{6}$, the 170 and 300 . The amino acid residues of the two heparin binding sites, namely, site 170 and site 300can form a connecting bridge with the variant of $\mathrm{CD}_{44 \mathrm{v} 3}$. In addition, in the RGD fragment and $\mathrm{CD}_{44}$ binding site, there is a recognition site, containing integrin $\beta_{1}$.During the period of appearing tumor, the functional area of $\mathrm{N}$ terminal can have relation with the spread of tumors. The functional area of $C$ terminal can be related to the immune escape; RGD structure can play an important role for the adhesion function of OPN. 


\section{OPN and Diagnosis of Ovarian Cancer}

From April 2013 to March 2014, taking the thirty two cases of gynaecology surgery resection epithelial ovarian cancer specimens as experimental group from a Medical University Department. At the same time, selecting twenty cases of benign epithelial ovarian tumors (median age $43.4 \pm 0.81$ years old) and eight cases of normal ovarian tissue (median age of $52.8 \pm 0.3$ years old) as the control group, all the patients did not accept any radiotherapy and chemical therapy. In the experimental group, the age of patients can be ranged from 18 to 76 years old, and median age was $53.7 \pm 0.56$ years old.After operation, the standards of the International Federation of gynecology and Obstetrics (FIGO 2000) can be used to classify staging, including four cases of stage I; twelve patients in stage II; ten cases of stage III; six cases in stage IV; histological grade can be as follows: thirteen cases are in $G_{1}$ grade; ten cases are in $G_{2}$ grade, nine cases are in grade $G_{3}$; as for the aspect of lymph node metastasis: eight cases are positive and twenty four cases are negative. After having operation on resection of the primary lesion, it should immediately cut fresh ovarian tumor tissue as specimen, after washing with physiological saline, it should be stored immediately in liquid nitrogen at $-196 \quad{ }^{\circ} \mathrm{C}$.

This experiment adopts the reverse transcriptase polymerase chain reaction (RT-PCR) as the method, with the gel imaging analysis system, on gel doc 2000 analyzer, using BIOS consort 30 analysis software to compare the gene amplification bands with $\beta$-actin bands (the comparison ratio value is A), so as to compare the changes of A.

Statistical Method. The experimental data are measurement data, adopting $\mathrm{t}$ inspection and $\chi^{2}$ inspection.Using the statistical software SPSS 12.0 to have data processing, there is significant difference when $\mathrm{P}<0.05$, instead, when $\mathrm{P}>0.05$, there is no significant difference between the two groups.

\section{The Positive Expression Rate of OPN and CD44v6 in Different Ovarian Tissues}

Among thirty two cases of ovarian cancer specimens, there are thirty two cases that can be amplified bands of OPN, while thirty one cases can be amplified bands of $\mathrm{CD}_{44} \mathrm{~V}_{6}$. Among twenty cases of benign tumor specimens, there are nine cases can be amplified target gene; among eight cases of normal ovarian specimens, there are three cases can be amplified bands of OPN and two cases can be amplified bands of $\mathrm{CD}_{44} \mathrm{~V}_{6}$. The expression rate of OPN and $\mathrm{CD}_{44} \mathrm{~V}_{6}$ in ovarian epithelial cancer is $100 \%$ and $96.9 \%$ respectively, which is significantly higher than that in normal ovarian tissue (OPN is $37.5 \%, \mathrm{CD}_{44} \mathrm{~V}_{6}$ is $0 \%$ ) as well as in benign epithelial ovarian tumor tissue ( $\mathrm{OPN}$ is $55 \%, \mathrm{CD}_{44} \mathrm{~V}_{6}$ is $45 \%$ ), therefore the difference has statistically significance $(\mathrm{P}<0.05)$.

\section{The Relationship between OPN and CD44v6 in Ovarian Cancer}

By means of bivariate correlation analysis, it showed that ovarian cancer in the expression of OPN and expression of $\mathrm{CD}_{44} \mathrm{~V}_{6}$ can be positively correlated $(\mathrm{r}=0.35, \mathrm{P}<0.01)$, which can be shown in Table 1, indicating that the expression of OPN and expression of $C_{44} V_{6}$ can be related in ovarian cancer, the co-expression of them can have more significant meaning for predicting metastasis of ovarian cancer. 
Table 1 The Correlation between Expression of OPN and $\mathrm{CD}_{44} \mathrm{~V}_{6}$ in Ovarian Cancer Tissues The expression of OPN

The expression

of $\mathrm{CD}_{44} \mathrm{v}_{6}$

Negative Positive

Total Value of $x^{2} \quad P \quad r$

Negative

Positive
2

3

5
2

25

27

32

Note: $\mathrm{r}=0.35$, positive correlation, $\mathrm{P}<0.01$

\section{The Relationship between Clinic opathological Features and Expression of OPN and CD44v6 of Ovarian Cancer}

Among epithelial ovarian cancers, in different clinical stages between $\mathrm{OPN}$ and $\mathrm{CD}_{44} \mathrm{~V}_{6}$, there is different content of mRNA, for example, cases in late stage (III-IV) are significantly higher than that of early cases (I and II), there is significant difference $(\mathrm{P}<0.05)$, and the content of mRNA of $\mathrm{OPN}$ and $\mathrm{CD}_{44} \mathrm{~V}_{6}$ is related to the differentiation degree of the organization. The relative content in low differentiation group is significantly higher than that in high differentiation group, there is significant difference $(\mathrm{P}<0.05)$; the comparison between lymph node metastasis group and non-metastasis group, which also has significant difference $(\mathrm{P}<0.01)$; but the content of OPN and $\mathrm{CD}_{44} \mathrm{~V}_{6}$ has no significant difference with the patient's age, as well as the pathological type of tumors $(\mathrm{P}>0.05)$.

Table 2 The Expression of OPN and $\mathrm{CD}_{44} \mathrm{~V}_{6}$ in Different Ovarian Tissues

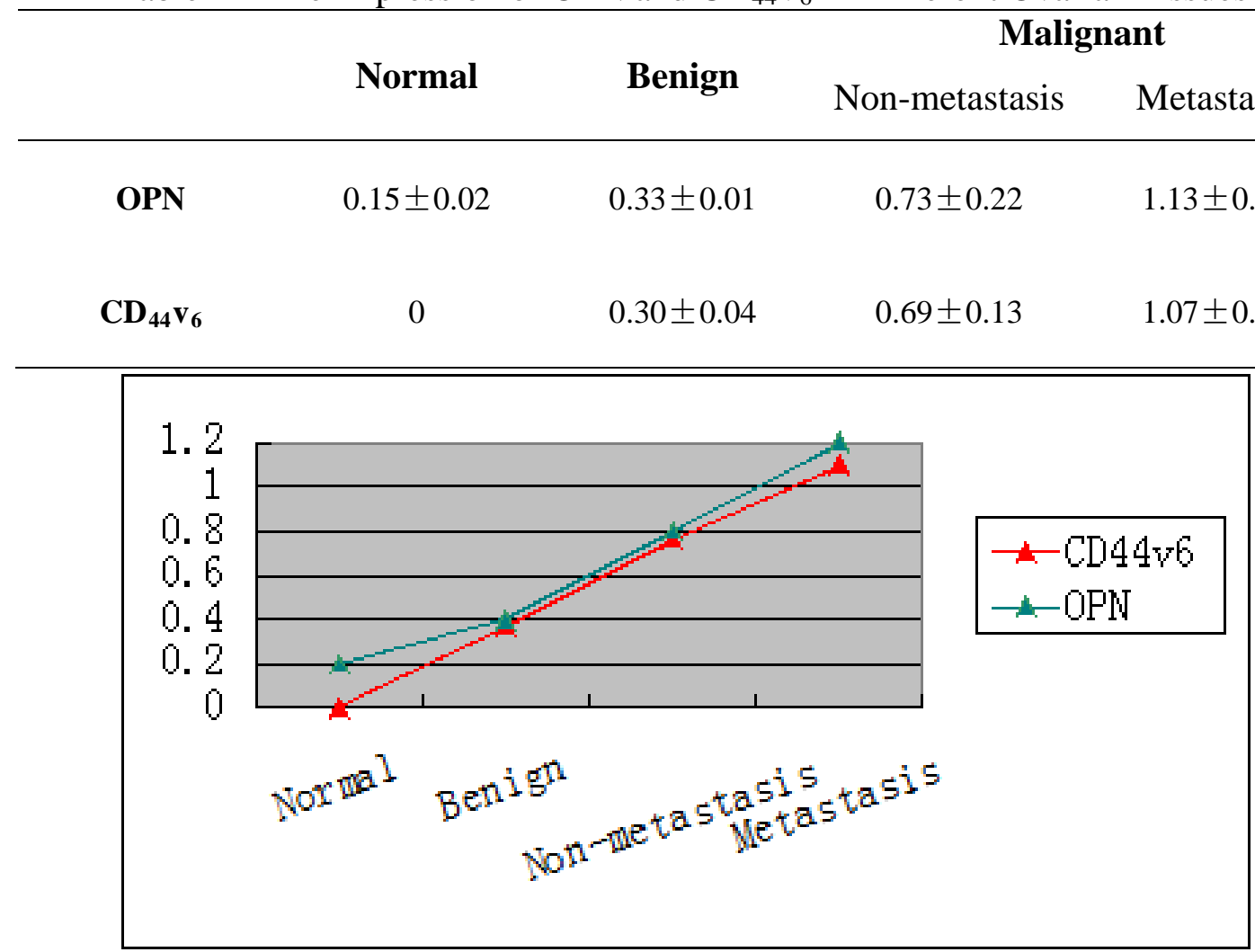

Fig. 1 The Content of $\mathrm{CD}_{44} \mathrm{~V}_{6}$, mRNA, OPN in Different Ovarian Tissues 


\section{Conclusion}

At present, the clinical principle on the diagnosis and treatment of malignant tumor is: striking for early detection, as early as possible to have surgical resection, aided with radiotherapy chemotherapy and supportive treatment, so as to take the improvement of life quality of the patients as the primary purpose. OPN as an important participant in the the mechanism of tumor metastasis, its peripheral blood concentration and receptor can be regarded as the cancer screening indicator for the non-destructive injury. As for the aspect of treatment, it explored the mechanism between osteopontin and $C_{44} \mathrm{~V}_{6}$, having intervention from gene starting to signal transduction pathway, which can effectively reduce the malignant degree of tumor, so as to prolong the survival time of patients and improve the quality of life.

\section{Reference}

[1]Tuck AB, Chambers AF. 2001. The role of osteopontin in breast cancer: clinical and experimental studies. J Mammary Gland Biol Neoplasia. vol.6, pp419-429.

[2]Tahara E. 2000. Molecular aspects of invasion and metastasis of stomach cancer. Verh Dtsch Ges Pathol. vol.84, pp43-49.

[3]Furger KA,Allan AL, Wilson SM, Hota C, Vantyghem SA, et al. 2003. Beta(3) integrin expression increases breast carcinoma cell responsiveness to the malignancy-ehhancing effects of osteopontin. Mol Cancer Res. vol.41, pp810-819.

[4]Bautista DS, Xuan JW, Hota C, et al. 1994. Inhibition of Arg-Gly-Asp(RGD)mediated cell adhesion to osteopontin by a monoclonal antibody against osteopontin. J Biol Chem. vol.269, 23280-23285.

[5]Katagiri YU, Sleeman J,Fujii H, et al. 1999. $\mathrm{CD}_{44}$ variants but not $\mathrm{CD}_{44} \mathrm{~S}$ cooperate with betal-containing integrins to permit cells to bind to osteopontin independently of arginine-glycine-aspartic acid,thereby stimulating cell motility and chemotaxis. Cancer Res. vol.59, pp219-226. 